\title{
STATUS DAN KENDALA KESUBURAN TANAH PADA LAHAN TEGALAN DAN KEBUN CAMPURAN DI KECAMATAN BLANG BINTANG KABUPATEN ACEH BESAR
}

\author{
(Status and Constraints of Soil Fertility in Dry land and mixed garden in Blang \\ Bintang Aceh Besar)
}

\author{
Ayuni Winazira ${ }^{1}$, Ilyas ${ }^{1}$, Sufardi $^{1 *}$ \\ ${ }^{1}$ Program Studi Ilmu Tanah, Fakultas Pertanian, Universitas Syiah Kuala \\ *Corresponding author: sufardi_usk@unsyiah.ac.id
}

\begin{abstract}
Abstrak. Lahan kering di Indonesia terutama di Aceh memiliki potensi yang sangat tinggi, namun umumnya lahan kering memiliki status kesuburan tanah rendah. Penelitian ini bertujuan untuk mengetahui status dan kendala kesuburan tanah pada lahan kering di Kecamatan Blang Bintang Kabupaten Aceh Besar Provinsi Aceh. Penelitian ini dilakukan dengan menggunakan metode deskriptif yang difokuskan pada dua tipe penggunaan lahan kering yaitu penggunaan lahan kebun campuran dan tegalan/tanaman semusim. Parameter yang diukur dalam penelitian ini meliputi: $\mathrm{pH}$, C-organik, $\mathrm{P}_{2} \mathrm{O}_{5}, \mathrm{~K}_{2} \mathrm{O}$, P tersedia, K-dd, Ca-dd, Mg-dd, Na-dd, Al-dd, KTK dan KB. Berdasarkan hasil penelitian, penggunaan lahan kebun campuran termasuk kedalam kriteria status kesuburan tanah rendah sedangkan tegalan tergolong ke dalam kriteria dengan status kesuburan tanah sedang. Faktor penghambat yang menjadi kendala kesuburan tanah pada kering di Kecamatan Blang Bintang yaitu rendahnya kandungan C-organik dan kejenuhan basa (KB) tanah. Selain itu, nilai $\mathrm{pH}$ tanah yang tergolong masam hingga agak masam juga menjadi salah satu kendala kesuburan tanah pada lahan kering Kecamatan Blang Bintang.
\end{abstract}

Kata kunci: Status, Kendala Kesuburan, Tegalan, Kebun Campuran.

Abstract. Dry land in Indonesia, especially in Aceh, has very high potential, but generally dry land has low soil fertility status. This study aims to determine the status and constraints of soil fertility on dry land in Blang Bintang District, Aceh Besar District, Aceh Province. This research was conducted using a descriptive method that focused on two types of dry land use, namely mixed garden land use and moor/seasonal crops. The parameters measured in this study included: $\mathrm{pH}, \mathrm{C}$-organic, $\mathrm{P} 2 \mathrm{O}$, $\mathrm{K} 2 \mathrm{O}$, available $\mathrm{P}, \mathrm{K}$-dd, Ca-dd, Mg-dd, Nadd, Al-dd, CEC and KB. Based on the results of the study, the use of mixed garden land was included in the criteria for low soil fertility status, while moor was included in the criteria with moderate soil fertility status. Inhibiting factors that become an obstacle to soil fertility in dry areas in Blang Bintang District are the low content of C-organic and alkaline saturation (KB) of the soil. In addition, the $\mathrm{pH}$ value of the soil which is classified as acidic to slightly acidic is also an obstacle to soil fertility in the dry land of Blang Bintang District.

Keywords: Status, Soil Fertility, Dry land, Mixed Garden.

\section{PENDAHULUAN}

Indonesia merupakan negara dengan lahan kering yang sangat luas. Lahan kering merupakan sebuah hamparan lahan yang tidak pernah tergenang atau digenangi air pada sebagian waktu dalam setahun (Sukarman et al., 2012). Dataran Indonesia seluas 191,1 juta ha, sebagian besarnya terdiri dari lahan kering seluas 1445,5 juta ha dan lahan basah seluas 46,6 juta ha.

Menurut Pusat Data Informasi Pertanian (2013) dari 1.140.584,54 ha lahan pertanian yang ada di Provinsi Aceh, sekitar 89.227,34 ha merupakan lahan kering. Meskipun potensi lahan kering di Aceh dan khususnya di Kabupaten Aceh Besar relatif luas, namun pemanfaatan lahan kering untuk pengembangan tanaman pangan masih rendah. Hal ini dakarenakan adanya beberapa kendala yang menjadi faktor penghambat pertumbuhan tanaman seperti kandungan bahan organik yang rendah, minimnya keberadaan organisme dalam tanah, dan tingkat kemasaman tanah yang tinggi. Selain tingkat kesuburan tanahnya 
yang rendah, lahan kering umumnya memiliki kelerengan yang curam, sehingga besar kemungkinan terjadinya erosi, terutama jika diusahakan untuk tanaman pangan semusim.

Berdasarkan uraian tadi, maka diperlukan evaluasi status kesuburan tanah, pada penggunaan lahan kering di Kabupaten Aceh Besar sehingga dapat diketahui status kesuburan tanahnya serta kendala yang dihadapi. Sehingga nantinya petani dapat memilih sistem dan teknologi tertentu untuk meningkatkan produksi, khususnya bagi petani pada lahan kering. Oleh karena itu, penting mengetahui status kesuburan tanah, agar lahan pertanian dapat dimanfaatkan secara berkelanjutan di masa yang akan datang.

\section{METODE PENELITIAN}

\section{Tempat dan Waktu Penelitian}

Penelitian ini dilaksanakan di Kecamatan Blang Bintang Kabupaten Aceh Besar Provinsi Aceh. Penelitian ini fokuskan pada dua tipe penggunaan lahan kering di Kecamatan Blang Bintang Kabupaten Aceh Besar. Selain di lapangan, penelitian ini juga dilakukan di Laboratorium Penelitian Tanah dan Tanaman Fakultas Pertanian Universitas Syiah Kuala. Penelitian ini dilaksanakan mulai bulan Juni hingga Agustus 2020.

\section{Alat dan Bahan Penelitian}

Adapun peralatan yang digunakan di lapangan yaitu GPS, bor tanah, ring sampel, $\mathrm{pH}$ meter, meteran, plastik, karet, pisau, cangkul, dan abney level. Sedangkan peralatan yang digunakan di laboratorium untuk analisis tanah yaitu timbangan analitik, $\mathrm{pH}$ meter, oven, shaker, hot plate, hogonizer, unit destilasi, buret, beaker, spektofotometer dan AAS (atamic absorption spectrophotometer).

Bahan-bahan yang digunakan dalam penelitian ini meliputi: tanah yang diambil pada lapisan atas $(0-20 \mathrm{~cm})$, peta wilayah, google map, peta jenis tanah, peta tititk pengamatan dan berbagai bahan kimia yang akan digunakan pada saat survai tanah di lapangan seperti $\mathrm{H} 2 \mathrm{O} 210 \%, \mathrm{HCl} 1 \mathrm{~N}$, akuades serta bahan untuk analisis laboratorium.

\section{Metode Penelitian}

Penelitian ini dilaksanakan dengan menggunakan metode deskriptif yang didasarkan pada hasil survai dan pengamatan lapangan (field study) dan analisis laboratorium. Titik pengambilan sampel tanah ditetapkan dengan menggunakan metode purpossive sampling yaitu titik yang telah ditentukan pada areal lahan kering terpilih yang terdapat di Kecamatan Blang Bintang Kabupaten Aceh Besar.

Pengambilan sampel tanah untuk analisis sifat kimia dilakukan dengan pengeboran. Pengeboran tanah dilakukan untuk mengetahui tingkat ketebalan solum tanah. Pengambilan sampel di khususkan hanya pada lapisan tanah atas saja (top soil) dengan ketebalan $0-20 \mathrm{~cm}$. Setiap tipe penggunaan lahan (LUT) diambil 5 - 6 titik sampel yang kemudian dianalisis di laboratorium. Dari data hasil analisis tanah kemudian akan ditentukan status kesuburan pada tiap tipe penggunaan lahannya.

\section{Pengamatan Lapangan dan Pengambilan Sampel}

Pengamatan lapangan serta pengambilan sampel dilakukan pada setiap titik pengamatan (LUT) di wilayah Kecamatan Blang Bintang Kabupaten Aceh Besar. Pengambilan sampel tanah diambil pada kelerengan 0 sampai 15\% (datar sampai agak curam) mewakili jenis tanah Entisol dan Inceptisol. Tipe penggunaan lahan yang diteliti kebun campuran dan tegalan. 
Pengambilan sampel tanah dilakukan dengan cara pengeboran di titik-titik yang telah ditentukan berdasarkan peta kerja. Setiap tipe penggunaan lahan, diambil 5 - 6 titik sampel tanah pada kedalaman $0-20 \mathrm{~cm}$ dengan jarak antara satu titik dengan titik lainnya yaitu 50 meter. Sampel tersebut kemudian di analisis sifat-sifat kimia tanahnya di laboratorium. Parameter yang di ukur dalam penelitian ini meliputi: $\mathrm{pH}, \mathrm{C}$-organik, $\mathrm{P}_{2} \mathrm{O}_{5}, \mathrm{~K}_{2} \mathrm{O}, \mathrm{P}$ tersedia, K-dd, Ca-dd, Mg-dd, Na-dd, Al-dd, KTK dan KB

\section{HASIL DAN PEMBAHASAN}

\section{A. Status Kesuburan Tanah}

\section{Kebun Campuran}

Berikut disajikan tabel hasil analisis dari beberapa parameter kesuburan tanah untuk penggunaan lahan kebun campuran di lahan kering Kecamatan Blang bintang.

Tabel 1. Hasil Analisis Status Kesuburan Tanah pada Penggunaan Lahan Kebun Campuran

\begin{tabular}{|c|c|c|c|c|c|c|}
\hline \multirow[t]{2}{*}{ Parameter } & \multicolumn{5}{|c|}{ Sampel } & \multirow[t]{2}{*}{ Rata-rata } \\
\hline & $\mathrm{T} 1$ & $\mathrm{~T} 2$ & T 3 & $\mathrm{~T} 4$ & T 5 & \\
\hline $\mathrm{pH}\left(\mathrm{H}_{2} \mathrm{O}\right)$ & $6.26_{\mathrm{AM}}$ & $5.61_{\mathrm{AM}}$ & $6.38 \mathrm{AM}$ & $6.42_{\mathrm{AM}}$ & $5.57_{\mathrm{AM}}$ & $6.04_{\mathrm{AM}} \pm 0.42$ \\
\hline $\mathrm{pH}(\mathrm{KCl})$ & $4.98_{\mathrm{M}}$ & $4.72_{\mathrm{M}}$ & $5.14_{M}$ & $5.40_{M}$ & $4.67_{\mathrm{M}}$ & $4.98_{\mathrm{M}} \pm 0.30$ \\
\hline C-organik (\%) & $1.31_{\mathrm{R}}$ & $1.28_{\mathrm{R}}$ & $1.32_{\mathrm{R}}$ & $1.31_{\mathrm{R}}$ & $1.25_{\mathrm{R}}$ & $1.29 \mathrm{R} \pm 0.02$ \\
\hline $\mathrm{P}_{2} \mathrm{O}_{5}(\mathrm{mg} / 100 \mathrm{~g})$ & $51.52_{\mathrm{T}}$ & $27.60_{\mathrm{s}}$ & $97.52_{\mathrm{ST}}$ & $73.60_{\mathrm{ST}}$ & $27.60_{s}$ & $55.56 \mathrm{~T} \pm 30.27$ \\
\hline $\mathrm{K}_{2} \mathrm{O}(\mathrm{mg} / 100 \mathrm{~g})$ & $32.80_{\mathrm{S}}$ & $29.60_{\mathrm{S}}$ & $39.20_{\mathrm{S}}$ & $73.60_{\mathrm{ST}}$ & $28.80_{\mathrm{S}}$ & $40.80_{\mathrm{S}} \pm 18.79$ \\
\hline P tersedia (ppm) & $0.55_{\mathrm{SR}}$ & $1.00_{\mathrm{SR}}$ & $0.90_{\mathrm{SR}}$ & $0.95_{\mathrm{SR}}$ & $0.95_{\mathrm{SR}}$ & $0.87_{\mathrm{SR}} \pm 0.18$ \\
\hline $\mathrm{K}-\mathrm{dd}\left(\mathrm{cmol} \mathrm{kg}^{-1}\right)$ & $1.68_{\mathrm{ST}}$ & $0.76_{\mathrm{T}}$ & $0.85_{\mathrm{T}}$ & $1.49_{\mathrm{ST}}$ & $1.90_{\mathrm{ST}}$ & $1.34_{\mathrm{ST}} \pm 0.51$ \\
\hline Ca-dd $\left(\mathrm{cmol} \mathrm{kg}^{-1}\right)$ & $5.12_{\mathrm{R}}$ & $2.77_{\mathrm{R}}$ & $7.85_{\mathrm{S}}$ & $7.05_{\mathrm{S}}$ & $2.26_{\mathrm{R}}$ & $5.01_{\mathrm{R}} \pm 2.49$ \\
\hline $\mathrm{Mg}-\mathrm{dd}\left(\mathrm{cmol} \mathrm{kg}^{-1}\right)$ & $0.50_{\mathrm{R}}$ & $0.47_{\mathrm{R}}$ & $0.48_{\mathrm{R}}$ & $0.49_{\mathrm{R}}$ & $0.47_{\mathrm{R}}$ & $0.48_{\mathrm{R}} \pm 0.01$ \\
\hline $\mathrm{Na}-\mathrm{dd}\left(\mathrm{cmol} \mathrm{kg}{ }^{-1}\right)$ & $0.18_{R}$ & $0.19_{\mathrm{R}}$ & $0.17_{\mathrm{R}}$ & $0.16_{\mathrm{R}}$ & $0.18_{\mathrm{R}}$ & $0.18_{\mathrm{R}} \pm 0.01$ \\
\hline Al-dd $\left(\mathrm{cmol} \mathrm{kg}^{-1}\right)$ & tu & $\mathrm{tu}$ & tu & tu & $\mathrm{tu}$ & - \\
\hline $\mathrm{KTK}\left(\mathrm{cmol} \mathrm{kg}^{-1}\right)$ & $22.00_{\mathrm{S}}$ & $15.20_{\mathrm{R}}$ & $22.80_{\mathrm{S}}$ & $24.40_{\mathrm{S}}$ & $15.20_{\mathrm{R}}$ & $19.90_{\mathrm{S}} \pm 4.39$ \\
\hline $\mathrm{KB}(\%)$ & $34.00_{\mathrm{R}}$ & $27.57_{R}$ & $41.01_{\mathrm{S}}$ & $37.66_{\mathrm{s}}$ & $31.64_{R}$ & $34.30_{\mathrm{R}} \pm 5.21$ \\
\hline
\end{tabular}

Hasil analisis $\mathrm{pH} \mathrm{H} 2 \mathrm{O}$ pada penggunaan lahan kebun campuran di lahan kering Kecamatan Blang Bintang dikategorikan masam sampai agak masam. Nilai $\mathrm{pH}$ pada ke lima titik penelitian berkisar antara 5,61 - 6,42 dengan $\mathrm{pH}$ rata-ratanya mencapai 6,04 yang juga tergolong agak masam. Sedangkan hasil analisis $\mathrm{pH} \mathrm{KCl}$ pada ke lima titik penelitian tergolong masam sampai agak masam, berkisar antara 4,67 - 5,40 dengan rata-rata nilainya yaitu 4,98 .

Sulakhudin et al. (2014) menyatakan bahwa nilai $\mathrm{pH}$ penting untuk penentuan hara tanaman sebagai media tumbuh tanaman, beberapa unsur hara yang diperlukan keberadaannya sangat tergantung pada $\mathrm{pH} . \mathrm{pH}$ tanah yang rendah akan menyebabkan tanaman tidak dapat memanfaatkan unsur $\mathrm{N}, \mathrm{P}, \mathrm{K}$, dan zat hara lain yang dibutuhkan. Rendahnya $\mathrm{pH}$ juga menyebabkan tersedianya unsur beracun seperti alumunium yang selalu meracuni tanaman dan juga mengikat fosfor sehingga tidak efektif diserap oleh tanaman (Ali dan Dengiz, 2019).

Hasil analisis menunjukkan bahwa kandungan C-organik pada ke lima titik penelitian pada penggunaan lahan kebun campuran di lahan kering Kecamatan Blang Bintang tergolong rendah. Kandungan C-organik pada ke lima titik penelitian berkisar antara 1,25-1,32\% 
dengan rata-rata nilainya yaitu 1,36\% yang juga tergolong rendah. Rendahnya kandungan Corganik pada tanah lokasi penelitian mencerminkan produksi bahan organik pada tanah penelitian yang juga tergolong rendah. Hal ini menjadikan salah satu kendala kesuburan tanah pada penggunaan lahan kebun campuran di lahan kering Kecamatan Blang Bintang. Oleh karena itu, perlu dilakukannya penambahan bahan organik ke dalam tanah. Selain meningkatkan kadar C-organik, Sufardi (2012) menyebutkan penambahan bahan organik ke dalam tanah juga menjadi sumber utama pembentukan koloid humus.

Hasil analisis kandungan P-tersedia pada penggunaan lahan kebun campuran Kecamatan Blang Bintang tergolong sangat rendah, berkisar 0,76-1,90 ppm dengan rata-rata nilainya yaitu $0,87 \mathrm{ppm}$. Fosfor di dalam tanah terdapat dalam berbagai bentuk persenyawaan yang sebagian besar tidak tersedia bagi tanaman. Sebagian besar pupuk yang diberikan ke dalam tanah, tidak dapat digunakan tanaman karena bereaksi dengan bahan tanah lainnya, sehingga nilai efisiensi pemupukan $\mathrm{P}$ pada umumnya rendah hingga sangat rendah (Henrique et al., 2016).

Hasil analisis sebaran P-total pada penggunaan lahan semak hutan di Kecamatan Blang Bintang tergolong beragam, mulai dari sedang, tinggi sampai sangat tinggi. Nilai P-total pada ke lima titik penelitian berkisar 27,60 - 97,52 mg/100g dengan rata-rata nilainya yang tergolong tinggi, yaitu $55,56 \mathrm{mg} / 100 \mathrm{~g}$. Kandungan $\mathrm{P}$ total di lokasi tanah penelitian tidak ditemukan adanya kandungan Phospat yang rendah pada setiap titik sampel yang diamati, sehingga menyebabkan tidak adanya faktor pembatas atau kendala kesuburan tanah di lokasi lahan kebun campuran ini sehingga tidak diperlukan penambahan cadangan fosfor ke dalam tanah. Unsur-unsur P di dalam tanah dapat berasal dari bahan organik seperti pupuk kandang dan sisa-sisa tanaman atau dari pupuk kimia (Selvaraj et al., 2019).

Hasil pengukuran menunjukkan bahwa kandungan K-total tanah dari setiap titik tergolong sedang kecuali pada sampel T4 yang tergolong sangat tinggi. Kandungan K-total pada ke lima titik penelitian berkisar 28,80 - 73,60 mg/100g, dengan rata-rata nilai K-totalnya yang juga tergolong sedang, yaitu $40,80 \mathrm{mg} / 100 \mathrm{~g}$. Salah satu penyebab tinggi rendahnya kalium di dalam tanah dipengaruhi oleh bahan induk dan juga $\mathrm{pH}$ tanah. $\mathrm{pH}$ tanah yang masam akan menyebabkan peningkatan fiksasi kalium sehingga menyebabkan penurunan ketersediaan unsur K dalam tanah, begitupun sebaliknya. Sebagian besar tanah memiliki unsur kalium yang cukup, hal ini diduga karena sumber K di dalam tanah merupakan mineral asli yang tidak mudah membusuk (Sufardi et al., 2018).

Berikutnya kadar kation basa tertukar (Ca-dd, Mg-dd, K-dd, dan Na-dd). Kadar K-dd pada tanah lokasi penelitian secara umum tergolong sangat tinggi. Tinggimya kadar K-dd ini menunjukkan bahwa ketersediaan kalium pada tanah lokasi penelitian tidak menjadi masalah. Sedangkan untuk kadar kation basa tertukar lainnya (Ca-dd, Mg-dd dan Na-dd) tergolong rendah sehingga masih di perlukannya pemberian pupuk yang berimbang.

Hasil pengukuran menunjukkam bahwasanya kadar aluminium yang dapat ditukar (Aldd) tidak terukur atau sangat rendah. Hal ini menunjukkan tidak ada potensi terjadinya keracunan Al pada tanaman.

Hasil pengukuran nilai KTK tanah pada ke lima titik pengambilan sampel tergolong rendah hingga sedang, berkisar antara $15,20-22,80 \mathrm{cmol} \mathrm{kg}$-1dengan rata-rata nilainya yaitu $19,90 \mathrm{cmol} \mathrm{kg-1yang} \mathrm{juga} \mathrm{tergolong} \mathrm{sedang.} \mathrm{Rendahnya} \mathrm{nilai} \mathrm{KTK} \mathrm{pada} \mathrm{titik} \mathrm{T2} \mathrm{dan} \mathrm{T5} \mathrm{dapat}$ disebabkan oleh $\mathrm{pH}$ tanah yang juga rendah (agak masam). Reaksi tanah sangat mempengaruhi nilai KTK tanah dan ketersediaan unsur hara yang terdapat dalam tanah, semakin tinggi pH maka nilai KTK tanah juga akan meningkat (Fayez et al., 2017).

Hasil pengukuran persentase $\mathrm{KB}$ tanah dari ke lima titik penelitian tergolong rendah hingga sedang, berkisar 31,88 - 47,92\% dengan rata-rata nilainya yaitu 34,30\% yang 
tergolong ke dalam kriteria rendah. Rendahnya persentase KB pada beberapa titik penelitian mencerminkan kandungan basa-basa dalam tanah masih sedikit, melihat daerah penelitian tergolong agak curam dan kemungkinan terjadinya erosi relatif besar.

\section{Tegalan/tanaman semusim}

Berikut disajikan tabel hasil analisis pada beberapa parameter kesuburan tanah pada lahan tegalan di lahan kering Kecamatan Blang Bintang yang ditanami tanaman pisang.

Tabel 2. Hasil Analisis Status Kesuburan Tanah pada Penggunaan Lahan Tegalan

\begin{tabular}{|c|c|c|c|c|c|c|c|}
\hline \multirow[t]{2}{*}{ Parameter } & \multicolumn{6}{|c|}{ Sampel } & \multirow[t]{2}{*}{ Rata-rata } \\
\hline & $\mathrm{T} 1$ & $\mathrm{~T} 2$ & $\mathrm{~T} 3$ & $\mathrm{~T} 4$ & $\mathrm{~T} 5$ & T 6 & \\
\hline $\mathrm{pH}\left(\mathrm{H}_{2} \mathrm{O}\right)$ & $6.52_{\mathrm{AM}}$ & $8.07_{\mathrm{AK}}$ & $6.33_{\mathrm{AM}}$ & $7.13_{\mathrm{N}}$ & $6.63_{\mathrm{AM}}$ & $6.14_{\mathrm{AM}}$ & $6.80_{\mathrm{N}} \pm 0.71$ \\
\hline $\mathrm{pH}(\mathrm{KCl})$ & $5.08_{\mathrm{M}}$ & $6.95_{\mathrm{N}}$ & $4.66_{\mathrm{AM}}$ & $5.73_{\mathrm{AM}}$ & $5.47_{\mathrm{M}}$ & $4.70_{\mathrm{M}}$ & $5.43_{\mathrm{M}} \pm 0.85$ \\
\hline C-organik & $1.76_{\mathrm{R}}$ & $1.31_{\mathrm{R}}$ & $1.34_{R}$ & $1.62_{\mathrm{R}}$ & $1.50_{\mathrm{R}}$ & $1.42_{\mathrm{R}}$ & $1.49_{\mathrm{R}} \pm 0.17$ \\
\hline $\mathrm{P}_{2} \mathrm{O}_{5}$ & $1.376 .32 \mathrm{ST}$ & $123.28_{\mathrm{ST}}$ & $171.12_{\mathrm{ST}}$ & $325.688_{\mathrm{ST}}$ & $117.76_{\mathrm{ST}}$ & $66.24_{\mathrm{ST}}$ & $363.40_{\mathrm{ST}} \pm 504.12$ \\
\hline $\mathrm{K}_{2} \mathrm{O}$ & $111.12_{\mathrm{ST}}$ & $424.00_{\mathrm{ST}}$ & $28.80_{\mathrm{s}}$ & $54.40_{\mathrm{T}}$ & $28.80_{\mathrm{s}}$ & $54.40_{\mathrm{T}}$ & $116.92_{\mathrm{ST} \pm 153.41}$ \\
\hline $\mathrm{P}$ tersedia & $0.55_{\mathrm{SR}}$ & $146.35_{\mathrm{ST}}$ & $3.40_{\mathrm{R}}$ & $66.95_{\mathrm{ST}}$ & $113.65_{\mathrm{ST}}$ & $19.80_{\mathrm{ST}}$ & $58.45_{\mathrm{ST}} \pm 61.19$ \\
\hline K-dd & $1.15_{\mathrm{ST}}$ & $1.38_{\mathrm{ST}}$ & $0.52_{\mathrm{S}}$ & $1.10_{\mathrm{ST}}$ & $0.98_{\mathrm{T}}$ & $1.37_{\mathrm{ST}}$ & $1.08_{\mathrm{ST}} \pm 0.32$ \\
\hline Ca-dd & $9.31_{\mathrm{s}}$ & $10.15_{\mathrm{s}}$ & $8.45_{\mathrm{s}}$ & $10.88_{\mathrm{S}}$ & $14.01_{\mathrm{T}}$ & $8.05_{\mathrm{s}}$ & $10.14_{s} \pm 2.17$ \\
\hline Mg-dd & $0.50_{\mathrm{R}}$ & $0.52_{\mathrm{R}}$ & $0.53_{R}$ & $0.53_{R}$ & $0.52_{\mathrm{R}}$ & $0.52_{\mathrm{R}}$ & $0.52_{\mathrm{R}} \pm 0.01$ \\
\hline Na-dd & $0.15_{\mathrm{R}}$ & $0.21_{R}$ & $0.18_{R}$ & $0.19_{R}$ & $0.19_{R}$ & $0.19_{\mathrm{R}}$ & $0.19_{R} \pm 0.02$ \\
\hline Al-dd & tu & tu & tu & tu & tu & tu & - \\
\hline KTK & $22.80 \mathrm{~s}$ & $27.60_{\mathrm{T}}$ & $19.60_{\mathrm{s}}$ & $25.20_{\mathrm{T}}$ & $26.00_{\mathrm{T}}$ & $24.00_{\mathrm{s}}$ & $24.20_{\mathrm{s}} \pm 2.79$ \\
\hline $\mathrm{KB}$ & $48.73 \mathrm{~s}$ & $44.42 \mathrm{~s}$ & $49.39_{\mathrm{s}}$ & $50.40_{\mathrm{s}}$ & $60.38_{\mathrm{T}}$ & $42.21_{\mathrm{S}}$ & $49.25_{\mathrm{s}} \pm 6.30$ \\
\hline
\end{tabular}

Hasil analisis menunjukkan nilai pH $\mathrm{H} 2 \mathrm{O}$ pada lahan tegalan di lahan kering Kecamatan Blang Bintang dikategorikan netral hingga agak alkalis. Nilai $\mathrm{pH}$ pada ke enam titik penelitian berkisar antara 6,14-8,07 dengan $\mathrm{pH}$ rata-ratanya yaitu 6,80 yang juga tergolong netral. Sedangkan hasil analisis $\mathrm{pH} \mathrm{KCl}$ pada ke enam titik penelitian tergolong masam sampai agak masam, berkisar antara 4,66 - 6,95 dengan rata-rata nilainya yaitu 5,43. (Romig, 1995 dalam Salma et al., 2016) menyatakan bahwa tanah dapat dikatakan sehat jika tanah tersebut memiliki $\mathrm{pH}$ netral, tanah dikatakan tidak sehat apabila memiliki $\mathrm{pH}$ tanah masam atau basa.

Hasil analisis menunjukkan bahwa kandungan C-organik pada ke enam titik penelitian di lahan kering Kecamatan Blang Bintang tergolong rendah. Kandungan C-organik pada ke enam titik penelitian berkisar antara $1,34 \%$ - $1,76 \%$ dengan rata-rata nilainya yaitu $1,56 \%$ yang juga tergolong rendah. Rendahnya kandungan C-organik di lokasi penelitian dapat disebabkan karena kurangnya keadaran petani akan pentingnya penambahan pupuk organik saat proses pengelolaan tanah. Penambahan bahan organik ke dalam tanah dapat menambah unsur hara bagi tanaman, meningkatkan kapasitas tukar kation tanah dan mampu menciptakan tanah yang subur serta sesuai untuk pertumbuhan tanaman (Fayez et al., 2017).

Hasil analisis kandungan P-tersedia di lahan tegalan pada ke enam titik penelitian di lahan kering Kecamatan Blang Bintang tergolong sangat rendah, rendah sampai sangat tinggi. Nilai P-tersedia tanah pada ke enam titik penelitian berkisar 0,55 - 113,65 ppm dengan ratarata nilainya yaitu $58,45 \mathrm{ppm}$ yang juga tergolong sangat tinggi. Nilai P-tersedia yang umumnya tinggi ini mencerminkan bahwa hara $\mathrm{P}$ tersedia secara cukup dan efektif untuk tanaman. 
Hasil analisis sebaran P-total pada ke enam titik penelitian di lahan tegalan Kecamatan Blang Bintang tergolong sangat tinggi. Nilai P-total pada ke enam titik penelitian berkisar 66,24 - 325,68 mg/100g dengan rata-rata nilainya yang juga tergolong sangat tinggi, yaitu mencapai 363,40 mg/100g. Tingginya nilai P-total pada lokasi penelitian menjadikan tidak adanya kendala kekurangan $\mathrm{P}$ pada lahan tegalan kebun pisang di lahan kering Kecamatan Blang Bintang.

Hasil pengukuran menunjukkan bahwa nilai K-total tanah dari setiap titik termasuk ke dalam kriteria sedang, tinggi hingga sangat tinggi. Nilai K-total pada ke enam titik penelitian berkisar $28,80-424,00 \mathrm{mg} / 100 \mathrm{~g}$, dengan rata-rata nilai K-totalnya yang juga tergolong sangat tinggi yaitu mencapai $116,92 \mathrm{mg} / 100 \mathrm{~g}$. Tingginya kadar kalium tanah pada lokasi penelitian dikarenakan besarnya nilai KTK pada daerah penelitian. Nilai KTK yang semakin tinggi mampu meningkatkan kapasitas tanah dalam menahan $\mathrm{K}$, sehingga tanah akan lambat melepaskan K dan menurunkan potensi pencucian (Dyah, 2015). Selain itu, penyebab lainnya nilai $\mathrm{K}$ yang tergolong tinggi yaitu banyaknya serasah tanaman dan kotoran sapi pada tanah lokasi penelitian sehingga hal ini menjadi salah satu sumber K untuk tanah.

Kadar kation-kation basa pada lokasi penelitian sangat bervariasi. Berdasarkan tabel 9 menunjukkan nilai K-dd dan Ca-dd tergolong ke dalam kriteria sedang, tinggi sampai sangat tinggi. Sehingga kalium dan kalsium tidak menjadi kendala pada tanah lokasi penelitian. Sedangkan nilai $\mathrm{Mg}$-dd tergolong ke dalam kriteria rendah. $\mathrm{Mg}$ termasuk dalam unsur hara makro sekunder yang diperlukan tanah dan tanaman untuk mengimbangi kelarutan $\mathrm{Fe}$ dan $\mathrm{Al}$ yang terlalu banyak pada tanah masam (Havlin et al., 2010; Sufardi, 2017). Oleh karena itu perlu dilakukannya pemupukan agar ketersediannya dalam tanah dan tanaman dapat tercukupi. Sama halnya dengan $\mathrm{Mg}$-dd, nilai $\mathrm{Na-dd} \mathrm{pada} \mathrm{tanah} \mathrm{lokasi} \mathrm{penelitian} \mathrm{juga}$ tergolong rendah, ini menunjukkan bahwa tidak ada indikasi pengaruh garam (Na) pada tanah sehingga hal ini tidak menjadi masalah bagi tanah dan tanaman.

Hasil pengukuran menunjukkam bahwasanya kadar aluminium yang dapat ditukar (Aldd) tidak terukur. Hal ini dapat disebabkan karena $\mathrm{pH}$ di lokasi penelitian berada di atas 5,5. Umumnya aktivitas $\mathrm{Al}$ akan meningkat pada $\mathrm{pH}$ lebih rendah dari 5,5.

Hasil pengukuran nilai KTK tanah pada lahan tegalan Kecamatan Blang Bintang yang diamati tergolong sedang sampai tinggi. Besarnya nilai KTK pada ke enam titik lokasi penelitian berkisar antara 19,60-27,60 cmol kg-1, dengan rata-rata nilainya yaitu $24,20 \mathrm{cmol}$ kg-1 yang juga tergolong sedang. Nilai KTK pada penggunaan lahan tegalan tidak temukan adanya KTK yang rendah, hal ini dapat disebabkan $\mathrm{pH}$ pada lokasi penelitian yang tergolong netral.

Hasil pengukuran persentase $\mathrm{KB}$ tanah pada lahan tegalan tergolong sedang kecuali pada titik sampel T5 yang tergolong tinggi, dengan persentase KB mencapai 60,38\%. persentase $\mathrm{KB}$ pada ke enam titik penelitian berkisar antara 42,21\% - 60.38\% dengan rata-rata nilainya yaitu $49,25 \%$ yang juga tergolong sedang. Semakin meningkatnya persentase KB tanah pada lahan tegalan kebun pisang ini dapat disebabkan oleh nilai $\mathrm{pH}$ pada lokasi penelitian yang termasuk ke dalam kriteria netral hingga agak alkalis. Semakin tinggi $\mathrm{pH}$, maka semakin tinggi pula persentase KB pada tanah lokasi penelitian. Selain itu, tingginya persentase $\mathrm{KB}$ pada penggunaan lahan tegalan juga di sebabkan karena lokasi penelitian berada pada kondisi tanah yang datar sehingga keadaan ini memberikan pengaruh sangat kecil terhadap hilangnya basa-basa tanah melalui erosi. 


\section{B. Evaluasi Status Kesuburan Tanah}

Hasil evaluasi status kesuburan tanah pada dua penggunaan lahan kering di Kabupaten Aceh Besar didasarkan atas kriteria penilaian sifat kimia tanah (PPT, 1995) terhadap 5 parameter tercantum pada Tabel 3.

Tabel 3. Kriteria Status Kesuburan Tanah Pada Dua Tipe Penggunaan Lahan Kering

\begin{tabular}{lcrrrrrr}
\hline & & \multicolumn{5}{c}{ Rata-rata } & \multicolumn{2}{c}{$\begin{array}{c}\text { Status } \\
\text { kesuburan tanah }\end{array}$} \\
\cline { 3 - 7 } & $\begin{array}{c}\text { Tipe penggunaan } \\
\text { lahan }\end{array}$ & $\mathrm{KTK}$ & $\mathrm{KB}$ & $\mathrm{P}_{2} \mathrm{O}_{5}$ & $\mathrm{~K}_{2} \mathrm{O}$ & $\begin{array}{c}\mathrm{C}- \\
\text { organik }\end{array}$ & \\
\hline 1 & Kebun campuran & $19.90_{\mathrm{S}}$ & $34.30_{\mathrm{R}}$ & $55.56_{\mathrm{T}}$ & $40.80_{\mathrm{S}}$ & $1.29_{\mathrm{R}}$ & Rendah \\
2 & Tegalan & $24.20_{\mathrm{S}}$ & $49.25_{\mathrm{S}}$ & $363.40_{\mathrm{ST}}$ & $116.92_{\mathrm{ST}}$ & $1.49_{\mathrm{R}}$ & Sedang \\
\hline
\end{tabular}

Berdasarkan hal tersebut, kriteria status kesuburan tanah yang diperoleh yaitu status kesuburan rendah pada penggunaan lahan kebun campuran, sedangkan status kesuburan tanah sedang terdapat pada penggunaan lahan tegalan. Rendahnya tingkat kesuburan tanah pada ke enam lokasi penelitian disebabkan oleh beberapa faktor penghambat, yaitu kandungan Corganik tanah yang rendah dan rendahnya persentase KB tanah pada beberapa penggunaan lahan kering di Kecamatan Blang Bintang Kabupaten Aceh Besar. Salah satu penyebab rendahnya kandungan C-organik pada lahan kering Kecamatan Blang Bintang Kabupaten Aceh Besar dikarenakan kelerengan yang tergolong agak curam, sehingga besar kemungkinan terjadinya pencucian melalui erosi. Saat hujan turun, lapisan atas tanah akan kehilangan unsur hara dan bahan organik yang terangkut bersama terjadinya erosi tanah.

Penyebab lainnya C-organik tanah yang rendah yaitu minimnya ketersediaan air pada lahan kering Kecamatan Blang Bintang sehingga proses pelarutan hara menjadi terhambat. Oleh karena itu diperlukan usaha korservasi tanah dan air untuk menjamin ketersedian air, mencegah terjadinya erosi, memelihara seta mampu memperbaiki tanah yang rusak.

Penambahan bahan organik ke dalam tanah sangat penting dilakukan karena bahan organik tanah dapat menciptakan kondisi tanah yang subur. Salah satu upaya yang dapat dilakukan untuk meningkatkan kualitas dan status kesuburan tanah adalah dengan penambahan bahan ameliorant seperti pupuk hayati dan biochar (Sufardi et al., 2018). Penambahan bahan organik secara teratur sangat di butuhkan agar kadar bahan organik dalam tanah tercukupi dan seimbang dan untuk mengurangi kadar bahan organik yang hilang dari tanah, khususnya pada kondisi tanah yang terdegradasi.

Selanjutnya, kejenuhan basa (KB) juga merupakan salah satu petunjuk untuk mengetahui status kesuburan tanah. Suatu tanah dikatakan sangat subur jika KB >70, apabila KB tanah berkisar 51 - 70 maka tanahnya memiliki kriteria sedang dan apabila KB tanah $<50$ maka tanah tergolong dalam kriteria tidak subur (Sufardi et al., 2018). Rendahnya nilai KB tanah pada daerah penelitian manunjukkan sedikitnya jumlah basa dalam tanah, hal ini diduga karena proses pencucian. Berdasarkan penelitian ini, dapat dikatakan bahwa tanah dengan kejenuhan basa (KB) yang rendah merupakan salah satu kendala yang terdapat pada lahan kering Kabupaten Aceh Besar terutama di Kecamatan Blang Bintang, karena nilai KB tanah mencerminkan jumlah kation yang dipertukarkan yang menempati koloid tanah (Bohn et al., 2010; Sufardi et al., 2018)

Selain itu penyebab persentase KB rendah dapat disebabkan karena sebagian besar lahannya merupakan daerah dengan kelerengan yang agak curam sampai curam dan kemungkinan terjadinya erosi relatif besar. Selain itu, rendahnya nilai KB pada daerah penelitian juga disebabkan $\mathrm{pH}$ tanah yang tergolong rendah. Menurunnya kemasaman tanah 
(pH netral) maka kesuburan akan meningkat dengan meningkatnya KB (Andrews et al., 2004). Untuk meningkatkan kejenuhan basa tanah, upaya yang dapat dilakukan yaitu dengan pemberian kapur seperti CaCO3 yang mampu menjadi sumber basa untuk tanah (Tan, 1991).

Berdasarkan uraian di atas, menunjukkan bahwasanya evaluasi status kesuburan tanah sangat penting untuk dilakukan agar kita dapat menentukan nilai potensi suatu lahan untuk tujuan tertentu. Pengetahuan tentang status kesuburan tanah suatu lahan sangat dibutuhkan dan di harapkan bagi pengguna lahan dapat mengusahakan lahan tersebut sesuai kemampuannya atau memilih input teknologi yang sesuai dengan status kesuburan tanah pada lokasi tertentu terutama pada lahan kering.

\section{KESIMPULAN DAN SARAN}

Status kesuburan tanah di Kecamatan Blang Bintang Kabupaten Aceh Besar tergolong kedalam dua kriteria. Penggunaan lahan kebun campuran tergolong ke dalam kriteria dengan status kesuburan tanah rendah sedangkan tegalan tergolong ke dalam kriteria dengan status kesuburan tanah sedang. Faktor penghambat yang menjadi kendala rendahnya status kesuburan tanah ialah kandungan $\mathrm{C}$-organik tanah dan kejenuhan basa (KB) dan yang termasuk ke dalam kriteria rendah.

Arahan pengelolaan kesuburan tanah untuk tipe penggunaan lahan dengan status kesuburan tanah rendah, berupa tindakan penambahan bahan organik, pengapuran serta usaha konservasi tanah dan air untuk meningkatkan status kesuburan tanahnya.

\section{DAFTAR PUSTAKA}

Ali, I dan O. Dengiz. 2019. Evaluation of soil quality index to assess the influence of soil degradation and desertification process in sub-arid terrestrial ecosystem. 30: 723-734.

Andrews, S.S., D.L. Karlen, and C.A. Cambardella. 2004. The soil management assessment framework. Soil Science Society of America Journal. 68: (19) 451-962.

Fayez, R. 2017. A minimum data set and soil quality index to quantify the effect of land use conversion on soil quality and degradation in native rangelands of upland arid and semiarid regions. (75): 307-320.

Pusat Data dan Sistem Informasi Pertanian. 2013. Statistik Lahan Pertanian Tahun 20082012. Sekretariat Jendral Pertanian 2013.

Salma S., Ulfiyah A. R., dan Isrun. 2016. Soil Quality Evaluation on Some Types of Land Use in Sigi Biromaru Distric Sigi Regency. Universitas Tadulako. 4 (6): 712-718.

Selvaraj, A., C. Chinnadurai., and D. Balachandar. 2019. Balachandar. Development of a soil biological quality index for soils of semi-arid tropics. Department of Agricultural Microbiology, Tamil Nadu Agricultural University (TNAU).

Sufardi., M. Khalil., Darusman., M. R. Husni., S. Zakaria et al. 2018. Soil Fertility on Dryland Areas of Bireuen District Aceh Province. Banda Aceh.

Sufardi, S., M. Muyassir, dan L. Martunis. 2017. Pertukaran kation pada beberapa jenis tanah di Kabupaten Aceh Besar Provinsi Aceh (Indonesia). Dalam Seminar Prosiding Nasional Pascasarjana Unsyiah.

Sufardi., T. Arabia., Khairullah., Karnilawati., dan Z. Fuadi. 2018. Soil Physical and Chemical Properties of Several Soil Order in Suboptimal Dryland of Aceh Besar District, Indonesia. International Workshop and Seminar "Innovation of Environmental Friendly Agricultural Technology Supporting Sustainable Food SelfSufficiency. Surakarta. Indonesia. 
Sufardi, Darusman, Zaitun, S. Zakaria, T. F. Karmil. 2017. Soil chemical properties on dryland areas in Aceh Besar District (Indonesia). Proceeding of International Conference of Sustainable Agriculture, Yogyakarta, Indonesia.

Sukarman, I. G. M., Subika dan S. Ritung. 2012. Identifikasi Lahan Kering Potensial untuk Pengembangan Tanaman Pangan. Badan Litbang Pertanian, Kementrian Pertanian Republik Indonesia.

Sulakhudin., Denah, S., D., Sutarman, G. 2014. Kajian status kesuburan tanah pada lahan sawah di kecamatan Sungai kunyit kabupaten menpawah. Jurnal Pedon Tropika. 1 (3) :106-114. 